\title{
Do Physicians' Implicit Views of African Americans Affect Clinical Decision Making?
}

\author{
M. Norman Oliver, MD, MA, Kristen M. Wells, MPH, PhD, Jennifer A. Joy-Gaba, PhD, \\ Carlee Beth Hawkins, MA, and Brian A. Nosek, PhD
}

Background: Total knee replacement (TKR) is a cost-effective treatment option for severe osteoarthritis (OA). While prevalence of $\mathrm{OA}$ is higher among blacks than whites, TKR rates are lower among blacks. Physicians' implicit preferences might explain racial differences in TKR recommendation. The objective of this study was to evaluate whether the magnitude of implicit racial bias predicts physician recommendation of TKR for black and white patients with $\mathrm{OA}$ and to assess the effectiveness of a web-based instrument as an intervention to decrease the effect of implicit racial bias on physician recommendation of TKR.

Methods: In this web-based study, 543 family and internal medicine physicians were given a scenario describing either a black or white patient with severe $\mathrm{OA}$ refractory to medical treatment. Questionnaires evaluating the likelihood of recommending TKR, perceived medical cooperativeness, and measures of implicit racial bias were administered. The main outcome measures included TKR recommendation, implicit racial preference, and medical cooperativeness stereotypes measured with implicit association tests.

Results: Subjects displayed a strong implicit preference for whites over blacks $(P<.0001)$ and associated "medically cooperative" with whites over blacks $(P<.0001)$. Physicians reported significantly greater liking for whites over blacks $(P<.0001)$ and reported believing whites were more medically cooperative than blacks $(P<.0001)$. Participants reported providing similar care for white and black patients $(P=.10)$ but agreed that subconscious biases could influence their treatment decisions $(P<$ .0001). There was no significant difference in the rate of recommendation for TKR when the patient was black $(47 \%)$ versus white $(38 \%)(P=.439)$, and neither implicit nor explicit racial biases predicted differential treatment recommendations by race $($ all $P>.06)$. Although participants were more likely to recommend TKR when completing the implicit association test before the decision, patient race was not significant in the association $(P=.960)$.

Conclusions: Physicians possessed explicit and implicit racial biases, but those biases did not predict treatment recommendations. Clinicians' biases about the medical cooperativeness of blacks versus whites, however, may have influenced treatment decisions. (J Am Board Fam Med 2014;27:177-188.)

Keywords: African Americans, Health Care Disparities, Minority Health, Race, Racial Bias

Osteoarthritis (OA) is a leading cause of physical disability among older adults in the United States, often leading to significant pain, swelling, and reduced motion at the joint. Total knee replacement

This article was externally peer reviewed.

Submitted 27 November 2012; revised 30 August 2013; accepted 4 September 2013.

From the Department of Family Medicine (MNO, KMW) and the Department of Psychology (CBH, BAN), University of Virginia, Charlottesville; and the Virginia Commonwealth University, Richmond (JAJ-G).

Funding: This work was completed under ARRA Stimulus Funding award no. ZC10017.

Conflict of interest: The senior author (BAN) is an officer of Project Implicit Inc., a nonprofit organization that includes in its mission "To develop and deliver methods for investigating and applying phenomena of implicit social cognition, including
(TKR) is a cost-effective treatment option for moderate to severe knee $\mathrm{OA},{ }^{1-3}$ relieving pain and improving quality of life. Despite these benefits, marked disparities in TKR utilization in patients with OA exist by age, sex, geographic location, and racial category. While the rate of diagnosed OA is generally higher among African Americans than whites, ${ }^{4,5}$ African Americans receive TKR less than half as often as whites. ${ }^{6-11}$ These racial and ethnic

especially phenomena of implicit bias based on age, race, gender or other factors."

Corresponding author: M. Norman Oliver, MD, MA, Department of Family Medicine, Box 800729, Health System, University of Virginia, Charlottesville, VA 22908 (E-mail: noliver@virginia.edu). 
disparities remain after controlling for health insurance status, ${ }^{12}$ overall health, ${ }^{13}$ and disease severity. $^{13}$

Other factors that may account for this disparity include patient preferences and physician recommendation bias. Physicians' treatment planning may be unintentionally influenced by race or without them being aware of the bias. Implicit racial biases favoring whites compared with blacks are pervasive in the general population ${ }^{14}$ and among physicians. ${ }^{15}$ Racial biases of health care providers may play a role in the unequal treatment of minority populations and subsequent health disparities. ${ }^{16-24}$ Racial bias has been identified as a factor in the delivery of care for cardiovascular disease, ${ }^{25}$ pain management, ${ }^{26}$ and mental health care. ${ }^{27}$

Implicit racial biases are related, but distinct from, explicit, self-reported racial biases, ${ }^{28}$ and both implicit and explicit biases predict behavior. ${ }^{29}$ Only 2 studies have been conducted that are of direct relevance to this report. The first was an Internet-based study of medical residents that evaluated the association between implicit racial bias and thrombolytic therapy of black and white patients presenting with symptoms of myocardial infarction. The differential likelihood of treating white patients and not treating black patients with appropriate thrombolytic therapy was positively related to the physicians' implicit racial biases. ${ }^{30}$ The second, by Haider et $\mathrm{al},{ }^{31}$ failed to replicate this result, finding that medical students' preference toward white patients did not result in a statistically significant variation in treatment decisions in a similar scenario.

There have been no objective assessments of the role of racial bias in the recommendation of patients for TKR. This study used a web-based survey instrument to evaluate whether implicit and explicit racial bias predicts recommendation of TKR for white and black patients with severe $\mathrm{OA}$ and assessed the effectiveness of the instrument as an intervention to decrease racial bias in treatment.

\section{Methods \\ Measures}

\section{Clinical Vignette}

A clinical vignette (Appendix 1) indicated diagnostic criteria for OA for which TKR would be an appropriate treatment recommendation. The validity of this vignette was vetted a priori by a panel of family physicians. The race of the patient (black or white) was indicated by a small photograph of a man in his 50 s or 60 s set immediately above the vignette. We avoided drawing attention to race in the vignette to minimize suspicion of the purpose of the study. Otherwise, participants may have invoked deliberate strategies to avoid bias that they would not in normal contexts. To elicit variation in the likelihood of recommending TKR, the vignette was written such that other recommendations were possible. Overall, $44 \%$ of doctors recommended TKR.

A family physician or general internist would refer a patient to a surgeon for TKR, but primary care physicians often discuss with their patients the pros and cons of procedures, operations, and treatments that will be performed by specialists. In the clinical vignette, participants were guided through such a discussion.

\section{Implicit Association Test}

The Implicit Association Test (IAT) ${ }^{32}$ is a widely used tool to measure implicit biases. ${ }^{33}$ An IAT measuring implicit attitudes toward racial groups, for example, compares the average time it takes respondents to categorize images of black and white Americans and words with a good and bad meaning (eg, wonderful, terrible) in 2 critical conditions. In one condition, participants categorize black faces and good words with one response key and white faces and bad words with a second response key. In the other condition, participants categorize white faces and good words with one key and black faces and bad words with the other key. In one study, $>70 \%$ of the $>700,000$ participants were faster in the second condition than the first, indicating stronger associations of good words with white faces compared with black faces. ${ }^{14}$ This occurs despite whether the respondent is aware of possessing the associations in memory and whether they actively agree or disagree with them. The IAT has been conducted more than 15 million times since its inception in 1998 (eg, Nosek, Banaji, \& Greenwald, ${ }^{33}$ Nosek et al, ${ }^{14}$ ), and a large literature examines its psychometric properties and validity (see Nosek, Hawkins, \& Frazier ${ }^{34,35}$ for recent reviews). There is substantial evidence that physicians can complete the measure effectively with valid results (Sabin et $\mathrm{al}^{15,36}$ ). We used the previously recommended IAT procedure ${ }^{33}$ and analysis protocol. $^{37}$ 
The Race Preference IAT used the racial category labels black American and white American (stimuli: faces of black and white men, respectively) and evaluative category labels good (word stimuli: friendly, pleasure, happy, smiling) and bad (word stimuli: angry, noxious, brutal, terrible). The race Medical Cooperativeness IAT utilized the same racial category labels and images and the categories medically cooperative (word stimuli: takes physical therapy, accepts steroid injections, accepts NSAIDs, welcomes surgery) and medically uncooperative (word stimuli: declines physical therapy, refuses steroid injections, refuses NSAIDs, opposes surgery).

\section{Survey Measures}

Explicit bias was assessed by asking respondents whether they prefer black or white people (5-point Likert scale and 10-point thermometer scale for feelings). Participants also were asked about their beliefs about patients' willingness to undergo surgery (5point Likert scale for both black and white patients), their opinions regarding the effectiveness of TKR, and opinions on unconscious bias and IATs before and after the test (see http://www.briannosek.com for a complete list of study materials).

\section{Procedure}

Participants read the same vignette but were randomly assigned a picture of a black or a white patient. Participants were randomly assigned to complete the IATs before (intervention condition) or after reading the vignette (control condition). Then, participants reported whether the patient's knee pain was the result of severe OA (using a 5 -point Likert scale), whether they would recommend TKR, the strength of their recommendation (using a 5-point Likert scale), and their explicit attitudes and beliefs about racial groups and the existence of implicit bias. To bolster the exposure of and education about implicit bias, the IAT ended with a debriefing that explained the differences between implicit and explicit biases and the possible role of implicit bias in decision making. All study methods were approved by the institutional review board at the University of Virginia, and all participants provided informed consent.

\section{Samples}

Two sampling methods were used for this study, with one change in the procedure between them. The samples are combined for primary reporting, and observed results did not differ meaningfully between the 2 samples when examined separately.

\section{Direct Recruiting}

We recruited 79 family medicine and internal medicine physicians from the University of Virginia Health System via an E-mail with a link to the study. Additional family medicine physicians were recruited at departmental "Grand Rounds" at the University of Virginia and at the Virginia Academy of Family Physicians annual meeting. All clinicians recruited through direct methods have a self-reported education level of MD and are likely to refer patients for TKR.

\section{Indirect Recruiting}

A second sample of clinicians was recruited through the volunteer participant pool at the Project Implicit website (https://implicit.harvard.edu/). Hundreds of thousands of volunteers visit Project Implicit each year and are educated about implicit biases and given an opportunity to participate in research. After registering, participants complete a short demographic questionnaire that includes questions about educational degree(s) attained and current occupation. Participants then are randomly assigned to a study from a pool of studies-these are sometimes unobtrusively selected based on their demographic responses.

For this study, respondents who reported their education level as MD and listed their current occupation as "health care-diagnosing and treating practitioners" during registration were eligible to be assigned to this study. Once assigned, the clinicians indicated whether they felt qualified to recommend TKR. Those who agreed continued to the study ( $\mathrm{n}=587)$; those who disagreed were assigned to another study. Participants were subsequently excluded if they indicated that they were not currently or had never been employed as medical professionals $(n=43)$ or reported their age as $\leq 22$ years old $(n=27)$, making it unlikely that they had completed medical school and residency. Another 53 participants dropped out of the study before viewing the patient vignette, leaving 464 participants. Other than these recruitment procedures, the study procedure was identical to the previous sample except, because of time constraints (Nosek, Sriram, \& $\mathrm{Umansky}^{38}$ ), the online participants completed only the Race Medical Cooperativeness IAT and not the Race Preference IAT. We prior- 
Table 1. Participants' Demographic Information

\begin{tabular}{lc}
\hline Characteristics & Patients, $\mathrm{n}(\%)$ \\
\hline Sex & \\
Male & $256(47)$ \\
Female & $272(50)$ \\
Race/ethnicity & \\
European American/white & $371(70)$ \\
African American/black & $34(6)$ \\
Asian/Pacific Islander & $69(13)$ \\
Hispanic/Latino & $27(5)$ \\
Mixed & $14(3)$ \\
Other/unknown & $13(2)$ \\
American Indian/Alaskan & $2(<1)$ \\
Specialty & \\
Family medicine & $163(58)$ \\
Internal medicine & $116(42)$ \\
African American patients by clinic (\%) & \\
$<10$ & $124(31)$ \\
10-19 & $51(13)$ \\
$20-29$ & $65(16)$ \\
$30-39$ & $60(15)$ \\
$40-49$ & $40(10)$ \\
$\geq 50$ & $64(16)$ \\
Identification with racial/ethnic identity & \\
Little identification & $132(35(3)$ \\
Moderate identification & $209(16)$ \\
Strong identification & \\
Socioeconomic level growing up & \\
Lower & \\
Lower-middle & \\
Middle & \\
Upper-middle & $(20)$ \\
Mean years in practice (SD) & \\
\hline
\end{tabular}

Percentages do not add up to 100 because of missing values and rounding.

$\mathrm{SD}$, standard deviation.

itized using the implicit measure that Green et al. ${ }^{30}$ demonstrated had a stronger effect: the Race Medical Cooperativeness IAT.

\section{Results}

Variation in degrees of freedom for inferential tests is due to nonresponses for some items. The average age of the participants was 39.16 years (standard deviation [SD], 11.52 years), and the mean number of years in medical practice was 12.05 (SD, 10.26 years) (Table 1).

\section{Analytical Approach}

The main dependent variables were diagnosis of osteoarthritis and TKR decision. Both of these were measured on 5-point Likert scales and analyzed using linear regression. TKR decision also was measured as a dichotomous variable (recommend TKR or not) and analyzed using logistic regression. Most of the racial attitudes and stereotypes (both implicit and explicit) were measured as relative preferences for white versus black people, and these items were analyzed for significant difference from the 0 point (indicating no preference between black and white people) with 1-sample $t$ tests $\left(\mathrm{H}_{0}=0\right)$. Warmth and medical cooperativeness also were assessed separately for black and white people, and differences between these means were tested with paired-samples $t$ tests. Patient race was a betweenparticipants manipulation, so differences in attitudes and stereotypes, as well as beliefs about treatment and one's own biases, based on whether participants viewed a white patient or a black patient in the vignette, was tested with 2 samples $t$ tests.

\section{Diagnosis of OA and TKR Decision}

On average, participants reported that it was "somewhat likely (60\% to $80 \%)$ )" to "very likely (>80\%)" that the vignette character Mr. Jackson's knee pain was due to OA. In total, 207 doctors (44\%) recommended TKR for Mr. Jackson. A similar question asked participants to characterize their recommendation for Mr. Jackson using a 5-point scale, from 1 (would definitely not recommend TKR) to 5 (would definitely recommend TKR), and the average response was the midpoint of the scale (unsure). The 5 -point scale had a bimodal distribution and was highly correlated with the dichotomous measure $(r=0.75 ; P>.0001)$. We report analyses of the dichotomous items; substantive results and interpretations were the same using the continuous variable.

\section{TKR Recommendation by Race and Exposure to Implicit Bias}

Previous research has shown that completing an IAT can be an intervention for reducing explicit biases. ${ }^{39}$ To test whether experiencing the IAT could also influence clinical decision making, we manipulated the order of the IATs and the TKR vignette and decision. We hypothesized that completing the IAT before making the TKR decision would reduce the effect of patient race on TKR 
Table 2. Implicit Association Test (IAT) Scores by Patient Race and Order of IAT

\begin{tabular}{|c|c|c|c|c|c|c|c|c|}
\hline & \multicolumn{4}{|c|}{ IAT Completed First } & \multicolumn{4}{|c|}{ Vignette Completed First } \\
\hline & \multicolumn{2}{|c|}{ Black Patients } & \multicolumn{2}{|c|}{ White Patients } & \multicolumn{2}{|c|}{ Black Patients } & \multicolumn{2}{|c|}{ White Patients } \\
\hline & Mean (SD) & No. & Mean (SD) & No. & Mean (SD) & No. & Mean (SD) & No. \\
\hline Medical cooperativeness & $0.19(0.39)$ & 112 & $0.30(0.43)$ & 107 & $0.21(0.43)$ & 104 & $0.23(0.40)$ & 103 \\
\hline Racial preference & $0.50(0.24)$ & 19 & $0.50(0.33)$ & 14 & $0.38(0.38)$ & 27 & $0.36(0.42)$ & 12 \\
\hline
\end{tabular}

Positive scores indicate stronger associations with white people and medically cooperative and white people and good.

$\mathrm{SD}$, standard deviation.

recommendations. There was a main effect of the order of the $\operatorname{IAT}\left(\chi^{2}(d f=1, \mathrm{n}=470)=5.33 ; P=\right.$ .02): participants were more likely to recommend TKR when they completed the IAT before the decision (50\%) versus after the decision (39\%). However, the order did not interact with patient race to predict TKR recommendation $\left(\chi^{2}[d f=1\right.$, $\mathrm{n}=470]=0.00 ; P=.96)$. Furthermore, the main effect of patient race on TKR recommendation was not statistically significant $(P=.73)$, indicating that there was no racial bias for TKR recommendation regardless of IAT order. Doctor age and sex were added as covariates to the model in which patient race predicted TKR recommendation. Age significantly predicted TKR recommendation $\left(\chi^{2}(d f=1\right.$, $\mathrm{n}=456)=5.81 ; P=.016)$ : older doctors were less likely to recommend TKR. Sex did not significantly predict TKR recommendation $\left(\chi^{2}(d f=1, \mathrm{n}=\right.$ 456) $=0.55 ; P=.458)$, nor did the addition of the covariates change the patient race effect $\left(\chi^{2}(d f=1\right.$, $\mathrm{n}=456)=0.32 ; P=.569)$. Patient race does not predict TKR decisions, even when restricting the sample to white doctors only $(\mathrm{n}=371)\left(\chi^{2}(d f=1\right.$, $\mathrm{n}=324)=0.02 ; P=.888)$.

\section{Implicit Racial Attitudes and Stereotypes}

A 1-sample $t$ test revealed that participants implicitly preferred white people to black people (mean, 0.43 ; SD, $0.34 ; t(71)=10.64 ; P<.0001 ; d=1.26)$. This IAT was administered only to the directly recruited sample. Similarly, participants showed a stronger implicit association with medical cooperativeness and white people than black people (mean, 0.23; SD, $0.41 ; t(425)=11.76 ; P<.0001$; $d=0.57)$. In both cases, as expected, IAT scores did not differ, despite whether they were administered before or after the vignette $(P=0.12$ and 0.62 , respectively) or whether the vignette presented a black or white patient $(P=0.91$ and 0.74 , respectively) (Table 2 ).
Next we tested whether implicit racial bias predicted TKR recommendation and whether this effect was moderated by the implicit bias education intervention. We also tested whether implicit cooperativeness stereotype predicted TKR recommendation. Our base model predicted TKR recommendation in a logistic regression from the main effects of patient race and order of the IAT and their interaction; then we added the main effect of the moderator along with all 2-way interactions and the 3-way interaction. Neither of the moderators produced significant main effects, nor did they moderate the effect of patient race on TKR recommendation (Table 3).

Table 3. Predicting Total Knee Replacement (TKR) Recommendation from Patient Race, Implicit Association Test (IAT) Order, and Implicit Racial Attitude and Stereotype Moderators

\begin{tabular}{lcc}
\hline & $\chi^{2}$ & $P$ Value \\
\hline Cooperativeness IAT $(\mathrm{n}=417)$ & & \\
Patient race main effect & 0.15 & .700 \\
Cooperativeness IAT main effect & 0.24 & .624 \\
Order main effect & 2.30 & .129 \\
Interactions & & \\
$\quad$ Patient race + cooperativeness IAT & 0.50 & .479 \\
$\quad$ Patient race + order & 0.20 & .652 \\
$\quad$ Order + cooperativeness IAT & 0.00 & .983 \\
$\quad$ Patient race + cooperativeness IAT + & 0.55 & .458 \\
$\quad$ order & & \\
Race preference IAT $(n=72)$ & & \\
Patient race main effect & 0.63 & .428 \\
Race preference IAT main effect & 1.75 & .185 \\
Order main effect & 3.11 & .078 \\
Interactions & & \\
$\quad$ Patient race + race preference IAT & 0.21 & .648 \\
$\quad$ Patient race + order & 0.07 & .796 \\
$\quad$ Order + race preference IAT & 2.26 & .133 \\
Patient race + race preference IAT + & 0.32 & .570 \\
$\quad$ order & & \\
\hline
\end{tabular}


Table 4. Participants' Explicit Attitudes Toward Patients

\begin{tabular}{lllll}
\hline Attitudes & No. & Overall & Black Patients & White Patients \\
\hline Explicit racial preference* $^{*}$ & 427 & $0.28(0.78)$ & $0.28(0.69)$ & $0.28(0.87)$ \\
Warmth toward black people $^{\dagger}$ & 427 & $6.99(1.80)$ & $6.90(1.73)$ & $7.08(1.88)$ \\
Warmth toward white people $^{\dagger}$ & 427 & $7.31(1.69)$ & $7.17(1.64)$ & $7.45(1.74)$ \\
Medically cooperative* $^{*}$ & 420 & $0.21(0.75)$ & $0.15(0.70)$ & $0.28(0.79)$ \\
Perception of black patients' medical cooperativeness $^{\dagger}$ & 425 & $6.22(1.42)$ & $6.21(1.42)$ & $6.24(1.42)$ \\
Perception of white patients' medical cooperativeness $^{\dagger}$ & 425 & $6.55(1.38)$ & $6.52(1.38)$ & $6.58(1.42)$ \\
Aggressive care* $^{*}$ & 427 & $0.04(0.41)$ & $0.04(0.38)$ & $0.03(0.44)$ \\
Subconscious biases affect my decisions $^{\dagger}$ & 428 & $3.64(1.12)$ & $3.51(1.17)$ & $3.78(1.05)$ \\
Treatment due to black patients' preferences $^{\dagger}$ & 215 & $3.26(1.25)$ & $3.19(1.31)$ & $3.33(1.20)$ \\
Treatment due to white patients' preferences $^{\dagger}$ & 211 & $3.14(1.26)$ & $3.11(1.30)$ & $3.18(1.21)$ \\
\hline
\end{tabular}

Data are mean (standard deviation) unless otherwise indicated.

*This scale is centered at zero, with positive values indicating more explicit preference for white people compared to black people, believing white people are more medically cooperative than black people, and providing more aggressive care for white people over black people.

${ }^{\dagger}$ Higher values indicate more warmth and more agreement that difference in treatment is due to patient preference.

\section{Self-Reported Attitudes}

Overall, a 1-sample $t$ test revealed that participants explicitly preferred white people to black people (mean, 0.28; SD, 0.78; $t(426)=7.46 ; P<.0001$; $d=0.36)$. Paired $t$ tests revealed that participants reported significantly higher feelings of warmth toward white people (mean, 7.31; SD, 1.69) than black people (mean, 6.99; SD, 1.80; $t(426)=4.96$; $P<.001 ; d=0.24)$.

In addition, in a 1-sample $t$ test participants explicitly reported that white patients were more medically cooperative than black patients $(P<$ .0001). Furthermore, when asked about white and black patients independently, paired $t$ tests revealed significantly more agreement that white patients were more medically cooperative (mean, 6.55 ; SD, 1.38) than black patients (mean, 6.22; SD, 1.42; $t(423)=5.80 ; P<.0001 ; d=0.28)$. Even so, participants reported providing similarly aggressive care for white patients and black patients (mean, -0.04 ; SD, 0.41); $t(426) \geq 1.89 ; P=.06 ; d=0.06)$.

Finally, using a 1-sample $t$ test, participants reported strong agreement that subconscious biases may influence their decision making (mean, 3.64; SD, $1.12 ; t(427)=11.79 ; P<.0001)$. Participants agreed that if black patients received differential medical treatment it could be because of their own preferences (mean, 3.26; SD, 1.25; $t(214)=2.99$; $P=.003 ; d=0.20)$. In contrast, participants neither agreed nor disagreed that white patients received differential medical treatment because of their own preferences (mean, 3.14; SD, 1.26; $t(210)=1.64 ; P=.10 ; d=0.11)$.
Interestingly, a 2-sample $t$ test revealed that participants who viewed a black patient in the vignette reported less agreement that biases could influence their decisions than participants who viewed a white patient $(P=.02)$, suggesting that exposure to a black patient may have increased reactance to the possibility of biases influencing behavior. However, there were no other significant differences in any attitudes or beliefs about bias by patient race condition (all $P \geq .08$ ). For a complete list of means, see Table 4 .

Explicit attitudes were standardized (SD, 1; retaining the rational zero point of "no preference" or "no difference" between blacks and whites) and averaged to create an aggregate score, indicating favorability for whites compared with blacks. (The questions included were, "Which of the following best describes your view about patients' cooperativeness with medical advice about interventions such as TKR?," "Please rate how cooperative you feel white patients are on average with medical advice about interventions such as TKR," "Please rate how cooperative you feel black patients are on average with medical advice about interventions such as TKR," "I provide less/similar/more aggressive care for white patients than I do for black patients," "I strongly prefer whites to blacks," "Please rate how warm or cold you feel toward white people," and "Please rate how warm or cold you feel toward black people.") For those topics that had separate items for blacks and whites, a difference score was calculated before standardizing. An intervention-by-patient race analysis of 
Table 5. Predicting Total Knee Replacement Recommendation from Patient Race, Order, and Explicit Racial Attitude Moderators

\begin{tabular}{lcc}
\hline & $\chi^{2}$ & $P$ Value \\
\hline Patient race main effect & 0.04 & 0.85 \\
Aggregated explicit attitudes main effect & 0.09 & 0.77 \\
Order main effect & 2.50 & 0.11 \\
Interactions & & \\
$\quad$ Patient race + aggregated explicit & 0.00 & 0.95 \\
$\quad$ attitudes & & \\
$\quad$ Patient race + order & 0.17 & 0.68 \\
$\quad$ Order + aggregated explicit attitudes & 1.68 & 0.20 \\
$\quad$ Patient race + order + aggregated & 0.22 & 0.64 \\
$\quad$ explicit attitudes & & \\
\hline
\end{tabular}

variance predicting this aggregate explicit attitude measure revealed no effect of intervention $(P=$ $.48)$, patient race $(P=.92)$, or their interaction $(P=.55)$ predicting explicit attitudes.

Furthermore, we examined whether explicit attitudes predicted TKR recommendation, using logistic regression with patient race, the aggregated explicit attitudes, the intervention condition, and their interactions as the independent variables predicting TKR recommendation (Table 5). The results suggest that explicit attitudes did not predict the TKR recommendation as a main effect or interaction with the other predictors.

\section{Beliefs About the Patient}

For a complete list of participants' beliefs about the patient in the scenario, see Table 4. Participants answered questions about treating the particular patient whose photograph appeared in the survey questionnaire. The race of the patient was never mentioned explicitly. Participants reported that they would feel more comfortable working with the black patient (mean, 4.34; SD, 0.82) compared with the white patient (mean, 4.16 ; SD, $1.02 ; t(457)=$ 2.06; $P=.04 ; d=0.10$ ). Results revealed no other significant differences based on the race of the patient (all $P \geq .07$ ).

We next tested whether the beliefs about the patient were affected by his race and the intervention. Beliefs about the patient were averaged to create an aggregate score indicating favorable beliefs about the patient. An intervention-by-patient race analysis of variance revealed no effect of intervention $(P=.70)$, patient race $(P=.82)$, or their interaction $(P=.11)$.
Table 6. Predicting Total Knee Replacement Recommendation from Patient Race, Order, and Aggregated Patient Belief Moderators

\begin{tabular}{lcc}
\hline & $\chi^{2}$ & $P$ Value \\
\hline Patient race main effect & 1.07 & .30 \\
Aggregated patient beliefs main effect & 6.01 & .01 \\
Order main effect & 0.09 & .77 \\
Interactions & & \\
$\quad$ Patient race + aggregated patient & 1.20 & .27 \\
$\quad$ beliefs & & \\
Patient race + order & 3.51 & .06 \\
$\quad$ Order + aggregated patient beliefs & 0.76 & .38 \\
Patient race + order + aggregated & 4.22 & .04 \\
$\quad$ patient beliefs & & \\
\hline
\end{tabular}

We also examined whether beliefs about the patient predicted TKR recommendation using logistic regression, with recommendation for TKR as the dependent variable and patient race, aggregated patient beliefs, and the intervention condition as independent variables (Table 6). The results revealed a significant 3 -way interaction $\left(\chi^{2}[d f=1\right.$, $\mathrm{n}=451]=4.22 ; P=.04)$, suggesting that in 3 of the conditions (those who received the vignette first and/or who viewed a white patient), physicians who reported more favorable beliefs about the patient were less likely to recommend TKR. In contrast, physicians who received the IAT first and viewed a black patient reported more favorable beliefs about the patient and were more likely to recommend TKR.

\section{Beliefs About the Educational Value of Learning About Bias}

See Appendix 2 for a full correlation matrix. Questions were centered so that a rating of zero indicated neither agreement nor disagreement, whereas positive values indicated agreement and negative values indicated disagreement. After completing the study, a 1-sample $t$ test revealed that participants agreed that subconscious biases could influence their decisions regarding patient care $(t(379)=13.04 ; P<.0001 ; d=0.67)$. Participants agreed that learning about subconscious biases could improve patient care $(t(377)=26.80 ; P<$ $.0001 ; d=1.38$ ).

Two-sample $t$ tests revealed that participants who viewed a white patient were significantly more likely to agree that subconscious bias influences their decisions (mean, 3.83; SD, 1.01) than partic- 


\begin{tabular}{lcrr}
\hline Beliefs & No. & Overall & Black Patients \\
\hline Subconscious biases influence my decisions & 380 & $0.72(1.07)$ & $0.62(1.13)$ \\
Learning about biases can improve patient care & 378 & $1.23(0.89)$ & $1.15(0.95)$ \\
IAT experience is worthwhile & 381 & $0.99(1.00)$ & $0.91(1.03)$ \\
Knowledge about what the study & 379 & $-1.37(1.47)$ & $-1.43(1.48)$ \\
The IAT results reflect my attitudes & 381 & $0.02(1.07)$ & $-1.98(1.10)$ \\
Would not have participated had I known & 379 & $-2.45(0.87)$ & $-2.44(0.88)$ \\
$\quad$ about the study's contents & & $-1.31(1.46)$ \\
\hline
\end{tabular}

Data are mean (standard deviation) unless otherwise indicated. Higher values indicate stronger agreement. IAT, implicit association test.

ipants who viewed a black patient (mean, 3.62; SD, $1.13 ; t(378)=1.93 ; P=.05 ; d=0.20)$. There were no other significant differences based on patient race (all $P \geq$.06), suggesting that whether participants viewed a black or white patient did not influence their remaining beliefs about the study (Table 7).

\section{Discussion}

Patient race did not affect the decision to recommend TKR for severe OA in the clinical vignette. However, physicians demonstrated implicit prowhite bias, reported an explicit preference for white people, had beliefs that blacks were less medically cooperative than whites, and believed that subconscious biases could influence their clinical decision making.

Although our study showed no main effect for race on clinicians' decision to recommend TKR, we found a suggestive 3-way interaction. When participants were presented with the clinical vignette before the IAT or with a white patient, or both of these conditions, they were more likely not to recommend TKR. When they were presented with the IAT first and a black patient, or both of these conditions, they were more likely to recommend TKR. One possible explanation for this finding is that the clinicians in the study felt that a medically cooperative or "good" patient would be able to manage their arthritis with conservative treatment-analgesic medication and physical therapy-rather than surgery. Patients thought to be medically uncooperative or "bad" patients would not do as well with conservative therapy and, therefore, should receive a recommendation for the more aggressive surgical option.

Another possible explanation for the lack of a main effect of patient race on TKR recommenda- tion is that the study population may be uniquely different from physicians included in prior studies. Our participants see a large proportion of black patients, with more than half of the participants reporting that $30 \%$ or more of their patients are African American. The proportion of blacks in the US population is $12 \%$, and the proportion in the catchment area of the practices of the physicians in our study is even less. Moreover, we found that the participants who were randomly assigned the black patient believed that they would feel more comfortable and confident working with him than those who were randomly assigned the white patient. Perhaps the fact that our physician participants see such a disproportionately high number of African American patients has led to effective compensatory strategies that mitigate effects of implicit and explicit biases when treating African Americans.

Alternatively, our clinical vignette may not have been sensitive enough to detect a racial difference. It was a single scenario and may not have sufficiently captured the realities of racial bias in clinical practice to detect an effect. An additional limitation is the inability to study the effect of sex on racial differences. However, adding a female vignette would require controlling for sex bias, and our study lacked sufficient power to examine both sex and racial biases simultaneously.

Another conclusion to be drawn from this research is the role of the IAT as an educational intervention to help physicians manage implicit racial bias. In the educational debriefing that followed the study, our participants felt that unconscious biases could affect clinical decision making. They also agreed that learning about such implicit biases could improve the care they provide to their patients. 


\section{Conclusion}

The conditions predicting when implicit biases will predict behavior or not are not yet fully understood. The lack of a significant correlation between our participants' implicit and explicit biases and their referral for TKR provides speculative opportunity to identify occasions where implicit biases do not affect clinical decision making or show their effect through other, less direct mechanisms. Studies of the possible role of implicit racial biases on clinical decision making should continue, and tools should be developed to help clinicians mitigate the effect of such biases on clinical practice.

\section{References}

1. Hawker G, Wright J, Coyte P, et al. Health-related quality of life after knee replacement. J Bone Joint Surg Am 1998;80:163-73.

2. Lavernia CJ, Guzman JF, Gachupin-Garcia A. Cost effectiveness and quality of life in knee arthroplasty. Clin Orthop Relat Res 1997;(345):134-9.

3. Miyasaka KC, Ranawat CS, Mullaji A. 10- to 20-Year follow-up of total knee arthroplasty for valgus deformities. Clin Orthop Relat Res 1997;(345):29-37.

4. Anderson JJ, Felson DT. Factors associated with osteoarthritis of the knee in the first National Health and Nutrition Examination Survey (NHANES I). Evidence for an association with overweight, race, and physical demands of work. Am J Epidemiol 1988;128:179-89.

5. Forman MD, Malamet R, Kaplan D. A survey of osteoarthritis of the knee in the elderly. J Rheumatol 1983;10:282-7.

6. Weinstein J. The Dartmouth atlas of musculoskeletal health care. Chicago: American Hospital Association Press; 2000.

7. Wilson MG, May DS, Kelly JJ. Racial differences in the use of total knee arthroplasty for osteoarthritis among older Americans. Ethn Dis 1994;4:57-67.

8. Katz BP, Freund DA, Heck DA, et al. Demographic variation in the rate of knee replacement: a multiyear analysis. Health Serv Res 1996;31:125-40.

9. McBean AM, Gornick M. Differences by race in the rates of procedures performed in hospitals for Medicare beneficiaries. Health Care Financ Rev 1994;15: 77-90.

10. Melzer D, Guralnik JM, Brock D. Prevalence and distribution of hip and knee joint replacements and hip implants in older Americans by the end of life. Aging Clin Exp Res 2003;15:60-6.

11. Dunlop DD, Song J, Manheim LM, Chang RW. Racial disparities in joint replacement use among older adults. Med Care 2003;41:288-98.

12. Jones A, Kwoh CK, Kelley ME, Ibrahim SA. Racial disparity in knee arthroplasty utilization in the Vet- erans' Health Administration. Arthritis Rheum 2005; 53:979-81.

13. Suarez-Almazor ME, Souchek J, Kelly PA, et al. Ethnic variation in knee replacement: patient preferences or uninformed disparity? Arch Intern Med 2005;165:1117-24.

14. Nosek BA, Smyth FL, Hansen JJ, et al. Pervasiveness and correlates of implicit attitudes and stereotypes. Eur Rev Soc Psychol 2007;18:36-88.

15. Sabin J, Nosek BA, Greenwald A, Rivara FP. Physicians' implicit and explicit attitudes about race by MD race, ethnicity, and gender. J Health Care Poor Underserved 2009;20:896-913.

16. Smedley BD, Stith AY, Nelson AR. Unequal treatment: confronting racial and ethnic disparities in health care. Washington, DC: National Academies Press; 2003.

17. Maynard C, Fisher LD, Passamani ER, Pullum T. Blacks in the coronary artery surgery study (CASS): race and clinical decision making. Am J Public Health 1986;76:1446-8.

18. Furth SL, Garg PP, Neu AM, Hwang W, Fivush BA, Powe NR. Racial differences in access to the kidney transplant waiting list for children and adolescents with end-stage renal disease. Pediatrics 2000;106: 756-61.

19. Epstein AM, Ayanian JZ, Keogh JH, et al. Racial disparities in access to renal transplantation-clinically appropriate or due to underuse or overuse? N Engl J Med 2000;343:1537-44.

20. Ayanian JZ, Weissman JS, Chasan-Taber S, Epstein AM. Quality of care by race and gender for congestive heart failure and pneumonia. Med Care 1999; 37:1260-9.

21. Einbinder LC SK. The effect of race on the referral process for invasive cardiac procedures. Med Care Res Rev 2000;57(Suppl 1):162-80.

22. Hannan EL, van Ryn M, Burke J, et al. Access to coronary artery bypass surgery by race/ethnicity and gender among patients who are appropriate for surgery. Med Care 1999;37:68-77.

23. Sedlis SP, Fisher VJ, Tice D, Esposito R, Madmon L, Steinberg EH. Racial differences in performance of invasive cardiac procedures in a Department of Veterans' Affairs medical center. J Clin Epidemiol 1997;50:899-901.

24. Whittle J, Conigliaro J, Good CB, Joswiak M. Do patient preferences contribute to racial differences in cardiovascular procedure use? J Gen Intern Med 1997; 12:267-73.

25. Schulman KA, Berlin JA, Harless $W$, et al. The effect of race and sex on physicians' recommendations for cardiac catheterization. $\mathrm{N}$ Engl J Med. 1999;340:618-26.

26. Weisse CS, Sorum PC, Sanders KN, Syat BL. Do gender and race affect decisions about pain management? J Gen Intern Med 2001;16:211-7. 
27. Lesko SM, Rosenberg L, Shapiro S. Family history and prostate cancer risk. Am J Epidemiol 1996;144: 1041-7.

28. Nosek BA, Smyth FL. A multitrait-multimethod validation of the implicit association test: implicit and explicit attitudes are related but distinct constructs. Exp Psychol 2007;54:14-29.

29. Greenwald AG, Poehlman TA, Uhlmann EL, Banaji MR. Understanding and using the implicit association test: III. Meta-analysis of predictive validity. J Pers Soc Psychol 2009;97:17-41.

30. Green AR, Carney DR, Pallin DJ, et al. Implicit bias among physicians and its prediction of thrombolysis decisions for black and white patients. J Gen Intern Med 2007;22:1231-8.

31. Haider AH, Sexton J, Sriram N, et al. Association of unconscious race and social class bias with vignettebased clinical assessments by medical students. JAMA 2011;306:942-51.

32. Greenwald A, McGhee D, Schwartz J. Measuring individual differences in implicit social cognition: the implicit association test. Am J Public Health 1998; $74: 1464-80$.

33. Nosek BA, Greenwald AG, Banaji MR. The implicit association test at age 7: a methodological and conceptual review. In: Bargh JA, editor. Social psychology and the unconscious: the automaticity of higher mental processes. New York: Psychology Press; 2007. p. 265-92.

34. Nosek BA, Hawkins CB, Frazier RS. Implicit social cognition: from measures to mechanisms. Trend Cogn Sci 2011;15:152-9.
35. Nosek BA, Hawkins CB, Frazier RS. Implicit social cognition. In: Fiske S, Macrae CN, editors. Handbook of social cognition. New York: Sage Publications, Inc.; 2012. p. 31-53.

36. Sabin JA, Marini M, Nosek BA. Implicit and explicit anti-fat bias among a large sample of medical doctors by BMI, race/ethnicity and gender. PLoS One 2012; 7:e48448.

37. Greenwald AG, Nosek BA, Banaji MR. Understanding and using the implicit association test: I. An improved scoring algorithm. J Pers Soc Psychol 2003;85:197-216.

38. Nosek BA, Sriram N, Umansky E. Presenting survey items one at a time compared to all at once decreases missing data without sacrificing validity in research with internet volunteers. PLoS One 2012;7:e36771.

39. Menatti A, Smyth FL, Teachman BA, Nosek BA. Reducing stigma toward individuals with mental illnesses: a brief, online manipulation. Stigma Res Action. In press.

\section{Appendix 1 \\ Clinical Vignette}

The patient is a 55 -year-old man with a history of right knee pain. Initially, the patient's knee pain was controlled with acetaminophen or ibuprofen. However, his knee pain now persists despite the use of nonsteroidal anti-inflammatory drugs, and the patient is requesting a stronger medication, "maybe with some codeine in it." He reports that "just walking to the mailbox is extremely painful." The patient has had 2 courses of physical therapy, with minor improvement in his knee pain. Recent radiographs of his right knee show significant narrowing of the joint space. 
Appendix 2

Overall Correlations

\begin{tabular}{|c|c|c|c|c|c|}
\hline Correlations & Race IAT & $\begin{array}{c}\text { Medical } \\
\text { Cooperativeness } \\
\text { IAT }\end{array}$ & $\begin{array}{l}\text { Aggregated Beliefs } \\
\text { about Patient }\end{array}$ & $\begin{array}{l}\text { Aggregated } \\
\text { Explicit } \\
\text { Beliefs }\end{array}$ & $\begin{array}{c}\text { TKR } \\
\text { Recommendation }\end{array}$ \\
\hline \multicolumn{6}{|l|}{ Overall } \\
\hline \multicolumn{6}{|l|}{ Race } \\
\hline IAT & 1.00 & $0.33^{*}$ & 0.03 & -0.07 & -0.07 \\
\hline No. & 72 & 67 & 71 & 64 & 72 \\
\hline \multicolumn{6}{|c|}{ Medical cooperativeness } \\
\hline IAT & 1.00 & 0.00 & $0.09^{\dagger}$ & -0.02 & \\
\hline No. & 426 & 414 & 401 & 417 & \\
\hline \multicolumn{6}{|c|}{ Aggregated beliefs about patient } \\
\hline IAT & & 1.00 & -0.08 & $-0.13^{*}$ & \\
\hline No. & & 455 & 412 & 451 & \\
\hline \multicolumn{6}{|c|}{ Aggregated explicit beliefs } \\
\hline IAT & & & 1.00 & 0.03 & \\
\hline No. & & & & 416 & 413 \\
\hline \multicolumn{6}{|c|}{ Intervention condition } \\
\hline \multicolumn{6}{|c|}{ Race } \\
\hline IAT & 1.00 & 0.18 & 0.25 & $-0.34^{\dagger}$ & $-0.29^{\dagger}$ \\
\hline No. & 33 & 32 & 33 & 32 & 33 \\
\hline \multicolumn{6}{|c|}{ Medical cooperativeness } \\
\hline IAT & & 1.00 & -0.06 & $0.12^{\dagger}$ & -0.03 \\
\hline No. & & 219 & 209 & 202 & 211 \\
\hline \multicolumn{6}{|c|}{ Aggregated beliefs about patient } \\
\hline IAT & & & 1.00 & -0.06 & -0.10 \\
\hline No. & & & 215 & 206 & 213 \\
\hline \multicolumn{6}{|c|}{ Aggregated explicit beliefs } \\
\hline IAT & & & & 1.00 & 0.09 \\
\hline No. & & & & 208 & 206 \\
\hline \multicolumn{6}{|c|}{ Control condition } \\
\hline \multicolumn{6}{|c|}{ Race } \\
\hline IAT & 1.00 & $0.42^{*}$ & -0.15 & 0.19 & 0.04 \\
\hline No. & 39 & 35 & 38 & 32 & 39 \\
\hline \multicolumn{6}{|c|}{ Medical cooperativeness } \\
\hline IAT & & 1.00 & 0.09 & 0.04 & -0.02 \\
\hline No. & & 207 & 205 & 199 & 206 \\
\hline \multicolumn{6}{|c|}{ Aggregated beliefs about patient } \\
\hline IAT & & & 1.00 & $-0.11^{\dagger}$ & $-0.16^{*}$ \\
\hline No. & & & 240 & 206 & 238 \\
\hline \multicolumn{6}{|c|}{ Aggregated explicit beliefs } \\
\hline IAT & & & & 1.00 & -0.04 \\
\hline No. & & & & 208 & 207 \\
\hline \multicolumn{6}{|c|}{$\begin{array}{l}\text { When participants view a white } \\
\text { patient }\end{array}$} \\
\hline \multicolumn{6}{|l|}{ Race } \\
\hline IAT & 1.00 & 0.19 & -0.13 & 0.05 & -0.08 \\
\hline No. & 26 & 41 & 46 & 40 & 26 \\
\hline
\end{tabular}

Continued 


\begin{tabular}{|c|c|c|c|c|c|}
\hline Correlations & Race IAT & $\begin{array}{c}\text { Medical } \\
\text { Cooperativeness } \\
\text { IAT }\end{array}$ & $\begin{array}{l}\text { Aggregated Beliefs } \\
\text { about Patient }\end{array}$ & $\begin{array}{l}\text { Aggregated } \\
\text { Explicit } \\
\text { Beliefs }\end{array}$ & $\begin{array}{c}\text { TKR } \\
\text { Recommendation }\end{array}$ \\
\hline \multicolumn{6}{|c|}{ Medical cooperativeness } \\
\hline IAT & & 1.00 & -0.01 & 0.09 & -0.05 \\
\hline No. & & 210 & 212 & 205 & 204 \\
\hline \multicolumn{6}{|c|}{ Aggregated beliefs about patient } \\
\hline IAT & & & 1.00 & $-0.11^{\dagger}$ & $-0.19^{*}$ \\
\hline No. & & & 215 & 200 & 213 \\
\hline \multicolumn{6}{|c|}{ Aggregated explicit beliefs } \\
\hline IAT & & & & 1.00 & 0.03 \\
\hline No. & & & & 203 & 201 \\
\hline \multicolumn{6}{|c|}{$\begin{array}{l}\text { When participants view a black } \\
\text { patient }\end{array}$} \\
\hline \multicolumn{6}{|c|}{ Race } \\
\hline IAT & 1.00 & 0.19 & -0.13 & 0.05 & -0.06 \\
\hline No. & 46 & 41 & 46 & 40 & 46 \\
\hline \multicolumn{6}{|c|}{ Medical cooperativeness } \\
\hline IAT & & 1.00 & -0.01 & 0.09 & 0.01 \\
\hline No. & & 216 & 212 & 205 & 213 \\
\hline \multicolumn{6}{|c|}{ Aggregated beliefs about patient } \\
\hline IAT & & & 1.00 & -0.04 & -0.07 \\
\hline No. & & & 240 & 212 & 238 \\
\hline \multicolumn{6}{|c|}{ Aggregated explicit beliefs } \\
\hline IAT & & & & 1.00 & 0.02 \\
\hline No. & & & & 213 & 212 \\
\hline
\end{tabular}

${ }^{*} P \leq .05$.

${ }^{\dagger} P \leq .10$.

IAT, implicit association test; TKR, total knee replacement. 